\title{
Metabolic disorders due to methanol poisoning
}

\author{
Tomas Salek ${ }^{\mathrm{a}}$, Petr Humpolicek, ${ }^{\mathrm{b}, \mathrm{c}}$ Petr Ponizil ${ }^{\mathrm{b}, \mathrm{d}}$
}

\begin{abstract}
Aim. The aim of this study is to compare markers of glomerular filtration rate (GFR), estimated GFR (eGFR), and metabolic parameters between admission and recovery in 13 patients of Tomas Bata hospital with methanol poisoning during methanol problems in the Czech Republic in 2012. The impact of methanol concentration and age on metabolic parameters were discovered at the time of admission to hospital.

Materials and Methods. The serum osmolality, methanol, ethanol, creatinine, cystatin C, Troponin I, ALT, plasma pH and lactate were measured in these 13 patients. The eGFR from serum creatinine (creatnine eGFR) and from cystatin C (cystatin C eGFR) were also determined.

Results. Increased serum osmolality and markers of metabolic acidosis are key indirect laboratory findings in patients with methanol poisoning. There were no significant changes in eGFR in our patients between admission and recovery. Increased serum troponin I concentration was confirmed as an indicator of myocardial necrosis in four patients. Two patients developed acute kidney injury (AKI) before admission.

Conclusions. We found statistically significant differences in serum osmolality concentration, plasma $\mathrm{pH}$ and lactate between admission and recovery. We found no changes in eGFR between admission and recovery. One patient had vision problems due to damage to the occipital lobes. Methanol poisoning may cause increase in markers of cardiac damage.
\end{abstract}

Key words: intoxication, osmolality, metabolic acidosis, creatinine, cystatin C

Received: May 10, 2013; Accepted with revision: September 19, 2013; Available online: September 27, 2013 http://dx.doi.org/10.5507/bp.2013.074

${ }^{a}$ Department of Clinical Biochemistry, Tomas Bata Regional Hospital in Zlin a.s., Zlin, Czech Republic

${ }^{b}$ Centre of Polymer Systems, Polymer Centre, Tomas Bata University in Zlín, Zlin

'Polymer Centre, Faculty of Technology, Tomas Bata University in Zlin, Zlin

${ }^{d}$ Department of Physics and Materials Engineering, Faculty of Technology, Tomas Bata University in Zlin, Zlin

Corresponding author: Tomas Salek, e-mail: t.salek@bnzlin.cz

\section{INTRODUCTION}

Methanol poisoning is a serious medical, social and economical problem. Mass methanol poisonings are rare but occur both in developed and developing countries ${ }^{1}$. Accidental cases of methanol poisoning are reported ${ }^{2}$. Suicide attempts using pure methanol are also presented in the literature ${ }^{3}$. Almost all cases of acute methanol toxicity result from accidental ingestion ${ }^{4}$. Methanol has relatively low toxicity and its metabolism is responsible for the transformation of methanol to its toxic metabolites, especially formic acid ${ }^{5}$. An interesting fact is that toxic and lethal doses of methanol have not hitherto been determined unequivocally. $15 \mathrm{~mL}$ of $40 \%$ methanol have caused death in some individuals, whereas others have survived consuming as much as $500 \mathrm{~mL}$ of such solution. These differences are probably caused by the simultaneous ethanol consumption, different folate content in the diet or the activity of methanol metabolism systems ${ }^{6}$. However, the minimal lethal dose of methanol in humans has been assumed to be $1 \mathrm{~g}$ per $\mathrm{kg}$ body weight (b.w.) in persons not having simultaneously consumed ethanol ${ }^{7}$.

Typical features of methanol intoxications include metabolic acidosis, hyperosmolality, increased osmolar gap, retinal damage with blindness, damage to putamen and caudate with neurologic dysfunction. Metabolic aci- dosis is caused by formic acid, lactic acid, and ketones. Methanol is oxidized by alcohol dehydrogenase to formaldehyde, which is then metabolized by formaldehyde dehydrogenase to formic acid. Formate acid is an inhibitor of mitochondrial cytochrome c oxidase which causes histotoxic hypoxia ${ }^{8}$. This leads to reduced adenosine triphosphate (ATP) production. Neurotoxic effects of formic acid to neurons and glial cells was also demonstrated in neural cultures ${ }^{9}$. The optic nerve is especially sensitive to reduced ATP production. This is due to its neurons' having long axons and very small diameter ${ }^{10}$. Brain changes can be demonstrated by computed tomography and magnetic resonance imaging ${ }^{11}$. Formate is also toxic to retinal cells ${ }^{12}$. There is a high level of free radical production during acute formic acid poisoning in animal models ${ }^{13}$. Formate is mainly responsible for metabolic acidosis $^{14}$. Differential diagnosis of alcohol drinkers with high levels of serum osmolality, increased osmolar gap and metabolic acidosis also include isopropyl alcohol intoxication ${ }^{15}$. Definitive diagnosis of methanol ingestion requires determination of methanol by gold standard test which is gas chromatography ${ }^{16}$. Acid base balance is frequently discussed in patients with methanol intoxication. Markers of GFR and cardiac damage are not discussed in the literature in such clinical situations. For this reason we evaluated these markers in this clinical setting. 


\section{MATERIAL AND METHODS}

The study included 13 patients with methanol poisoning at the Tomas Bata hospital in Zlin. There were 7 males and 6 females. The age of patients ranged from 28 to 79 years, mean 53 years. All patients survived. Two patients with the lowest methanol concentration were treated only with ethanol. Ten patients were treated with both hemodialysis and ethanol. One patient of this combination treatment group also had fomepizol. The onset of dialysis treatment ranged from $15 \mathrm{~min}$ to $6 \mathrm{~h}$ after admission. Serum osmolality was measured by freezing point depression. Serum methanol was measured by gas chromatography. Other serum markers were measured by automated Abbott Architect analyzer. Serum ethanol was determined by enzymatic photometry. Serum creatinine was measured by a standardized photometric enzymatic method traceable to NIST SRM 967 reference materi$\mathrm{al}^{17}$. Creatinine eGFR was estimated by the Lund Malmö equation ${ }^{18}$. Cystatin $\mathrm{C}$ was determined by a standardized immunoturbidimetric technique traceable to ERM DA 471/IFCC reference material ${ }^{19}$. Cysstatin C eGFR was calculated by equation validated for this method and analyser. Serum troponin I concentration was performed using immunochemiluminiscent technique. Serum alanin aminotransferase was determined by enzymatic method with pyridoxal phosphate activation. Plasma $\mathrm{pH}$ was determined by an electrochemical method on a Radiometer acid-base analyzer. We compared both creatinine eGFR and cystatin $\mathrm{C}$ eGFR in 13 methanol poisonings at admission and after recovery. We also compared osmolality, $\mathrm{pH}, \mathrm{ALT}$ and lactate between admission and recovery. We looked at serum troponin I concentration which is a marker of cardiomyocyte necrosis. We used Risk, Injury,
Failure, Loss, End-Stage Renal Disease (RIFLE) criteria for the diagnosis of acute kidney injur ${ }^{20}$. Urine output was measured over $\mathrm{ml} / \mathrm{kg} /$ hour in twelve patients. The clinical and laboratory status of one patient was so good that urine volume was not evaluated. The study was carried out according to the latest Declaration of Helsinki. It was approved by the Ethic Committee of Tomas Bata Hospital. We were allowed to collect and anonymously report the retrospective data of patients.

\section{Statistical evaluation}

Impact of methanol intoxication on metabolic markers was studied. These markers were followed: osmolality, Lactate and $\mathrm{pH}$. To discover the relationship between the level of methanol intoxication and these markers three statistical tests were used, paired t-tests for differences between the levels of individual markers at the beginning and at the end of hospitalization, correlations between individual markers, age of patients and methanol level $(\mathrm{mmol} / \mathrm{L})$ and linear regression with age and methanol level as fixed factors.

\section{RESULTS}

Key results of each patient are summarized in Table 1.

We found statistically significant differences in serum osmolality concentration, plasma $\mathrm{pH}$ and lactate between admission and recovery. The results of paired two-sample Student's t-test are shown in Table 2. A significant shift in osmolarity, lactate and $\mathrm{pH}$ level was found. The differences between the level of osmolality, $\mathrm{pH}$ and lactate at the beginning and at the end of therapy were significant at the $P \leq 0.01 ; P \leq 0.01$ and $P \leq 0.05$, respectively.

Table 1. Sex, age, methanol concentration and all studier markers at admission and discharge for each patient.

\begin{tabular}{|c|c|c|c|c|c|c|c|c|c|c|c|c|c|c|}
\hline \multirow[b]{2}{*}{$\underset{\varpi}{凶}$} & \multirow[b]{2}{*}{$\stackrel{8}{<}$} & \multirow{2}{*}{ 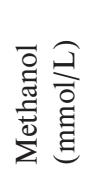 } & \multicolumn{2}{|c|}{$\begin{array}{c}\text { Cystatin C } \\
(\mathrm{mg} / \mathrm{L})\end{array}$} & \multicolumn{2}{|c|}{$\begin{array}{c}\text { Creatinine } \\
(\mu \mathrm{mol} / \mathrm{L})\end{array}$} & \multicolumn{2}{|c|}{$\begin{array}{l}\text { Osmolality } \\
(\mathrm{mmol} / \mathrm{kg})\end{array}$} & \multicolumn{2}{|c|}{$\begin{array}{c}\text { Lactate } \\
(\mathrm{mmol} / \mathrm{L})\end{array}$} & \multicolumn{2}{|c|}{$\mathrm{pH}$} & \multirow{2}{*}{ 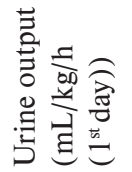 } & \multirow{2}{*}{$\frac{\sqrt[n]{\pi}}{\frac{\partial}{\pi}}$} \\
\hline & & & adm. & dis. & adm. & dis. & adm. & dis. & adm. & dis. & adm. & dis. & & \\
\hline $\mathrm{M}$ & 69 & 5 & 0.95 & 0.98 & 68 & 72 & 294 & 288 & & & 7.39 & 7.42 & 2.27 & No \\
\hline $\mathrm{F}$ & 58 & 76 & 0.77 & 0.90 & 71 & 58 & 390 & 281 & - & - & 7.11 & 7.47 & 1.72 & YES \\
\hline $\mathrm{F}$ & 63 & 55 & 1.12 & 0.92 & 79 & 56 & 373 & 288 & 0.9 & 1.4 & 7.09 & 7.41 & 4.67 & YES \\
\hline M & 42 & 12 & 0.66 & 0.63 & 73 & 75 & 303 & - & 1.5 & & 7.30 & 7.40 & 1.56 & YES \\
\hline $\mathrm{F}$ & 35 & 33 & 1.27 & 1.25 & 77 & 55 & 348 & 290 & 8.3 & & 7.08 & 7.42 & 0.57 & YES \\
\hline $\mathrm{M}$ & 48 & 62 & 1.68 & 0.62 & 167 & 44 & 374 & 280 & 7.6 & & 6.82 & 7.50 & 2.76 & YES \\
\hline $\mathrm{M}$ & 79 & 10 & 1.55 & 0.94 & 80 & 61 & 310 & 282 & 4.4 & 0.9 & 7.33 & 7.49 & 2.3 & YES \\
\hline $\mathrm{F}$ & 58 & 38 & 0.80 & 0.72 & 84 & 58 & 378 & 286 & 5.1 & 1.8 & 7.09 & 7.46 & 5 & YES \\
\hline M & 42 & 63 & 0.70 & 0.70 & 68 & 80 & 409 & - & 1.4 & - & 7.41 & 7.41 & 1.43 & YES \\
\hline $\mathrm{F}$ & 62 & 30 & 1.01 & 0.90 & 76 & 60 & 311 & 291 & 2.0 & 1.0 & 7.18 & 7.45 & 4.05 & YES \\
\hline M & 58 & 61 & 1.63 & 1.19 & 124 & 74 & 383 & 287 & 12.8 & 1.7 & 6.76 & 7.51 & 1.25 & YES \\
\hline $\mathrm{F}$ & 52 & 138 & 0.92 & 0.86 & 44 & 45 & 463 & 284 & 1.5 & 1.4 & 7.22 & 7.45 & 4.38 & YES \\
\hline M & 28 & 12 & 0.79 & 0.79 & 73 & 86 & 300 & 283 & 0.9 & 1.0 & 7.33 & 7.36 & - & No \\
\hline $\begin{array}{l}\text { Mean } \\
\pm \mathrm{SD}\end{array}$ & $\begin{array}{c}53.38 \\
\pm 14.15\end{array}$ & $\begin{array}{c}45.76 \\
\pm 36.50\end{array}$ & $\begin{array}{c}1.06 \\
\pm 0.35\end{array}$ & $\begin{array}{c}0.88 \\
\pm 0.19\end{array}$ & $\begin{array}{c}83.38 \\
\pm 30.50\end{array}$ & $\begin{array}{c}63.38 \\
\pm 12.98\end{array}$ & $\begin{array}{l}356.61 \\
\pm 51.01\end{array}$ & $\begin{array}{c}285.45 \\
\pm 3.70\end{array}$ & $\begin{array}{c}4.21 \\
\pm 3.90\end{array}$ & $\begin{array}{c}1.31 \\
\pm 0.36\end{array}$ & $\begin{array}{c}7.16 \\
\pm 0.20\end{array}$ & $\begin{array}{c}7.44 \\
\pm 0.04\end{array}$ & $\begin{array}{c}2.66 \\
\pm 1.50\end{array}$ & \\
\hline
\end{tabular}

adm. is the marker level at the admission time;

dis. is the marker level at the recovery time = discharge. 
Table 2. Average differences in marker levels at the beginning and at the end of therapy.

\begin{tabular}{cccccccc}
\hline $\begin{array}{c}\text { Cystatin } \mathrm{C} \\
(\mathrm{mg} / \mathrm{L})\end{array}$ & $\begin{array}{c}\text { Creatinine } \\
(\mu \mathrm{mol} / \mathrm{L})\end{array}$ & $\begin{array}{c}\text { Osmolality } \\
(\mathrm{mmol} / \mathrm{kg})\end{array}$ & $\begin{array}{c}\text { Lactate } \\
(\mathrm{mmol} / \mathrm{L})\end{array}$ & $\mathrm{pH}$ & ALT & $\begin{array}{c}\text { eGFR } \\
\text { Cystatin C }\end{array}$ & $\begin{array}{c}\text { eGFR } \\
\text { Creatinine }\end{array}$ \\
\hline $0.18 \pm 0.09$ & $20.00 \pm 9.88$ & $71.27 \pm 15.56^{* *}$ & $3.24 \pm 1.20^{*}$ & $-0.28 \pm 0.06^{* *}$ & $0.77 \pm 0.71$ & $-0.26 \pm 0.14$ & $-0.23 \pm 0.13$ \\
\hline
\end{tabular}

(Average change \pm standard error of the mean). The statistical differences by paired $t$-test ( $t$ value).

ALT is alanine aminotransferase; eGFR is estimated glomerular filtration rate.

* $P \leq 0.05, * * P \leq 0.01$.

The significant effect on the osmolality was subsequently confirmed by the correlation between osmolality and methanol level (Table $3, P \leq 0.01$ ).

The correlation between osmolality and methanol level was confirmed by the multiple correlation (Table 4). The correlation coefficient between osmolality and age methanol was 0.97 which, compared to the correlation to methanol only (Table 2; 0.95), showed a nonsignificant increase. The small impact of age was confirmed by partial correlation coefficient (Table 5) which confirmed the relations between the osmolality and methanol $(P \leq 0.01 ; \mathrm{r}=0.96)$ but not between age and methanol. Moreover, based on the linear regression we can state

Table 3. Correlation between the individual markers and age or methanol level.

\begin{tabular}{cccc}
\hline & $\begin{array}{c}\text { Osmolality } \\
(\mathrm{mmol} / \mathrm{kg})\end{array}$ & $\begin{array}{c}\text { Lactate } \\
(\mathrm{mmol} / \mathrm{L})\end{array}$ & $\mathrm{pH}$ \\
\hline $\mathrm{r}_{\text {age }}$ & -0.43 & -0.35 & 0.06 \\
$\mathrm{r}_{\text {met }}$ & $0.95^{* *}$ & 0.01 & -0.27 \\
\hline
\end{tabular}

$r_{\text {age }}$ is the Pearson correlation coefficient between age and marker $r_{\text {met }}$ is the Pearson correlation coefficient between methanol level and marker. $* * P \leq 0.01$ by testing for the significance of the correlation coefficient.

Table 4. Multiple correlation between the individual markers and combination of age with methanol.

\begin{tabular}{cccc}
\hline & $\begin{array}{c}\text { Osmolality } \\
(\mathrm{mmol} / \mathrm{kg})\end{array}$ & $\begin{array}{c}\text { Lactate } \\
(\mathrm{mmol} / \mathrm{L})\end{array}$ & $\mathrm{pH}$ \\
\hline $\mathrm{r}_{\text {met/age }}$ & $0.97 * *$ & 0.36 & 0.27 \\
\hline
\end{tabular}

$\mathrm{r}_{\text {met/age }}$ is the multiple correlation coefficient between age ant methanol level as independent variables and marker as dependent variable. $* * P \leq 0.01$ by testing for the significance of the muptiple correlation coefficient. that the increase in methanol level by $10 \mathrm{mmol} / \mathrm{L}$ will increase the osmolality about $13.0 \pm 1.4 \mathrm{mmol} / \mathrm{L}$. We found increased troponin I above $99^{\text {th }}$ percentile of healthy population in four patients (male 58 years old, females 58, 35 and 58 years old). None of the patients had clinical features of acute coronary syndrome and elctrocardiography showed no ischemic changes.

There was no difference in either creatinine eGFR or cystatin $\mathrm{C}$ eGFR between admission and recovery. Two patients had AKI according to RIFLE criteria. They met GFR criteria but not urine volume criteria (urine output below $0.5 \mathrm{~mL} / \mathrm{kg} / \mathrm{h}$ during hospital stay). AKI developed before admission to the hospital. Creatinine and cystatin $\mathrm{C}$ decreased and GFR increased in these two patients during treatment.

One patient - a 48 years old man - had vision problems. Magnetic resonance imaging of brain revealed cerebral white matter swellings (semioval center). Most of the impairments impacted the corona radiata center in the subcortical occipital regions. There was also haemorrhagicnecrosis of basal ganglia, especially putamen and the globus pallidus.

\section{DISCUSSION}

We compared metabolic parameters and markers of GFR between admission and discharge. We found increased serum osmolarity and metabolic acidosis in the majority of patients. It has been repeatedly reported, that serum osmolality increases with methanol poisoning ${ }^{21}$ and that methanol intoxication causes high anion gap metabolic acidosis ${ }^{22}$. The acidosis seen in early clinical course is caused directly by formic acid production. Lactate is produced later as formic acid interferes with intracellular respiration and promotes anaerobic metabolism ${ }^{5}$. These findings are seen in common clinical practice. Differential diagnosis of alcohol intoxication includes ethanol, ethylenglycol and isopropyl alcohol intoxication ${ }^{15}$.

Table 5. Partial correlation between the individual markers and age or methanol with removed effect of second variable.

\begin{tabular}{lclc}
\hline & Osmolality & Lactate & $\mathrm{pH}$ \\
\hline Rparc $_{\text {age }}$ & -0.622 & -0.361 & -0.010 \\
Rparc $_{\text {met }}$ & $0.964^{*}$ & -0.083 & -0.267 \\
\hline
\end{tabular}

Rparc $_{\text {age }}$ is partial correlation between marker and age (effect of methanol level is removed). $\mathrm{Rparc}_{\text {met }}$ is partial correlation between marker and methanol level (effect of age is removed).

$* P \leq 0.05$ by testing for the significance of the partial correlation coefficient. 
We found no statistically significant changes in eGFR. The small number of patients may also contribute to this result. Further, we are not able to accurately determine small GFR changes in patients on dialysis treatment. Two patients fullfilled the GFR criteria for AKI. We are unable to conclude that methanol intoxication caused this state. Dehydration could also have played a part in the development of AKI. Nephrotoxic drugs, sepsis and multiorgan dysfunction probably did not cause AKI in our patients. Acute renal failure developed in some studies in patients with methanol poisoning ${ }^{23}$. The limitation of our study is that we did not measure methanol and formic acid in urine. This could be useful to better understand the kinetics of methanol and formate elimination ${ }^{24}$.

Formate is especially toxic for nerve cells and the optic nerve. These cells need large amounts of energy. The inhibition of cytochrome c oxidase leads to low levels of ATP and cell dysfunction. The great sensitivity of the optic nerve to formate is well clinically documented in large epidemic problems in Cuba and in animal models ${ }^{10}$. Our patients were assessed by an ophthalmologist. One patient had vision problems. Magnetic resonance imaging of the brain revealed cerebral white matter swellings (semioval center). Most of the impairments impacted the corona radiata center in the subcortical occipital regions. There was also the hemoragic necrosis of the basal ganglia, especially the putamen and globus pallidus. Similar findings have been described in the literature ${ }^{11}$. Today, cardiac troponins are the gold standard for the diagnosis of myocardial necrosis ${ }^{25}$. We found no cardiac troponins in patients with methanol poisoning in the database of PubMed. Four of our patients had elevated serum levels of troponin I.

In summary, our results confirm well-known data on acid base and osmolarity disorders in patients with methanol poisoning. One new finding was elevation of troponin I in some patients. The major limitation of our study is the small number of patients and the fact that we do not measure serum or urine formic acid.

\section{CONCLUSIONS}

We found statistically significant differences in serum osmolality concentration, plasma $\mathrm{pH}$ and lactate between admission and recovery. We found no changes in eGFR between admission and recovery. We found increased serum troponin I concentration as an indicator of myocardial necrosis in four patients. One patient had vision problems due to damage to occipital lobes. This should be taken into account in treating these patients.

\section{ACKNOWLEDGEMENT}

Authorship contributions: All authors contributed equally to literature search, figures, data analysis, data interpretation, statistical analysis; TS, study design, data collection.

Conflict of interest statement: none declared.

\section{REFERENCES}

1. Paasma R, Hovda KE, Jacobsen D. Methanol Poisoning and Long Term Sequelae - a Six Years Follow-up after a Large Methanol Outbreak. BMC Clinical Pharmacology 2009;9:5. doi:10.1186/14726904-9-5

2. Epker JL, Bakker J. Accidental Methanol Ingestion: Case Report. BMC Emergency Medicine 2010;10:3. doi:10.1186/1471-227X-10-3

3. Bucaretchi F, De Capitani EM, Madureira PR, Cesconetto DM, Lanaro R, Vieira RJ. Suicide Attempt Using Pure Methanol with Hospitalization of the Patient Soon after Ingestion: Case Report. São Paulo Medical Journal = Revista Paulista de Medicina 2009;127:10810.

4. Xiao JH. Accidental Methyl Alcohol Poisoning. Zhonghua Yu Fang Yi Xue Za Zhi [Chinese Journal of Preventive Medicine] 1990;24:160-2.

5. Barceloux DG, Bond GR, Krenzelok EP, Cooper H, Vale JA. American Academy of Clinical Toxicology Ad Hoc Committee on the Treatment Guidelines for Methanol Poisoning. American Academy of Clinical Toxicology Practice Guidelines on the Treatment of Methanol Poisoning Journal of Toxicology. Clinical Toxicology 2002;40:415-46.

6. Bennett IL Jr, Cary FH, Mitchell GL Jr, Cooper MN. Acute Methyl Alcohol Poisoning: a Review Based on Experiences in an Outbreak of 323 Cases. Medicine 1953;32: 31-63.

7. Röe O, Enoksson P. Species Differences in Methanol Poisoning. Critical Reviews in Toxicology 1982;10:275-86. doi:10.3109/10408448209003368

8. Liesivuori J, Savolainen H. Methanol and Formic Acid Toxicity: Biochemical Mechanisms. Pharmacology \& Toxicology 1991;69:15763.

9. Dorman DC, Bolon B, Morgan KT. The Toxic Effects of Formate in Dissociated Primary Mouse Neural Cell Cultures. Toxicology and Applied Pharmacology 1993;122:265-72. doi:10.1006/ taap.1993.1195

10. Sadun A. Acquired Mitochondrial Impairment as a Cause of Optic Nerve Disease. Transactions of the American Ophthalmological Society 1998;96: 881-923.

11. Singh A, Samson R, Girdhar A. Portrait of a Methanol-intoxicated Brain. The American Journal of Medicine 2011;124:125-7. doi:10.1016/j.amjmed.2010.09.001

12. Treichel JL, Henry MM, Skumatz CM, Eells JT, Burke JM. Formate, the Toxic Metabolite of Methanol, in Cultured Ocular Cells. NeuroToxicology 2003;24:825-34. doi:10.1016/S0161-813X(03)00059-7

13. Dikalova AE, Kadiiska MB, Mason RP. An in Vivo ESR Spin-trapping Study: Free Radical Generation in Rats from Formate IntoxicationRole of the Fenton Reaction. Proceedings of the National Academy of Sciences 2011;98:13549-53. doi:10.1073/pnas.251091098

14. Kraut JA, Kurtz I. Toxic Alcohol Ingestions: Clinical Features, Diagnosis, and Management. Clinical Journal of the American Society of Nephrology 2008;3:208-25. doi:10.2215/CJN.03220807

15. Platteborze PL, Rainey PM, Baird GS. Ketoacidosis with Unexpected Serum Isopropyl Alcohol. Clinical Chemistry 2011;57:1361-4. doi:10.1373/clinchem.2010.157248

16. Anyfantakis D, Symvoulakis EK, Cristodoulakis EV, Frantzeskakis G. Ruling in the Diagnosis of Methanol Intoxication in a Young Heavy Drinker: a Case Report. Journal of Medicine and Life 2012;5:332-4.

17. Drion I, Cobbaert C, Groenier KH, Weykamp C, Bilo HJ, Wetzels JF, Kleefstra N. Clinical Evaluation of Analytical Variations in Serum Creatinine Measurements: Why Laboratories Should Abandon Jaffe Techniques. BMC Nephrology 2012;13:133. doi:10.1186/1471-236913-133

18. Björk J, Bäck SE, Sterner G, Carlson J, Lindstrom V, Bakoush O, Simonsson P, Grubb A, Nyman U. Prediction of Relative Glomerular Filtration Rate in Adults: New Improved Equations Based on Swedish Caucasians and Standardized Plasma-creatinine Assays. Scandinavian Journal of Clinical and Laboratory Investigation 2007;67:678-95. doi:10.1080/00365510701326891

19. Grubb A, Blirup-Jensen S, Lindström V, Schmidt C, Althaus $H$, Zegers I, IFCC Working Group on Standardisation of Cystatin C (WG-SCC). First Certified Reference Material for Cystatin $C$ in Human Serum ERM-DA471/IFCC. Clinical Chemistry and Laboratory Medicine: CCLM/FESCC 2010;48:1619-21. doi:10.1515/CCLM.2010.318

20. Eknoyan G, Lameire N, Eckardt KU, Kasiske BL, Kidney Disease: Improving Global Outcomes (KDIGO) Acute Kidney Injury Work Group. KDIGO Clinical Practice Guideline for Acute Kidney Injury. Kidney international Supplements 2012;2:1-138. 
21. Meatherall R, Krahn J. Excess Serum Osmolality Gap after Ingestion of Methanol. Clinical Chemistry 1990;36:2004-7.

22. Lim S. Metabolic Acidosis. Acta Medica Indonesiana 2007;39:145-50.

23. Verhelst D, Moulin P, Haufroid V, Wittebole X, Jadoul M, Hantson P. Acute Renal Injury Following Methanol Poisoning: Analysis of a Case Series. International Journal of Toxicology 2004;23:267-73. doi:10.1080/10915810490506795

24. Hovda KE, Mundal H, Urdal P, McMartin K, Jacobsen D. Extremely Slow Formate Elimination in Severe Methanol Poisoning: a Fatal
Case Report. Clinical Toxicology (Philadelphia, Pa.), 2007;45:516-21. doi:10.1080/15563650701354150

25. Thygesen K, Alpert JS, Jaffe AS, Simoons ML, Chaitman BR, White HD. Joint ESC/ACCF/AHA/WHF Task Force for the Universal Definition of Myocardial. Third Universal Definition of Myocardial Infarction. European Heart Journal 2012;33:2551-67. doi:10.1093/eurheartj/ ehs184

\section{LETTER TO THE EDITOR: METABOLIC DISORDERS DUE TO METHANOL INTOXICATION}

\section{Hossein Sanaei-Zadeh}

Correspondence: Dr Hossein Sanaei-Zadeh, Medical School, Shiraz University of Medical Sciences, Emergency Room/Division of Medical Toxicology, Hazrat Ali-Asghar (p) Hospital, Meshkinfam Street, 7143918796 Shiraz, Iran, e-mail: h-sanaiezadeh@ tums.ac.ir

\section{Dear Editor,}

I read with interest the study performed by Salek et al. recently published on-line in your journal ${ }^{1}$. Interestingly, the authors have been trying to evaluate changes in some metabolic parameters in methanol-poisoned patients that have been completely obvious from the very first beginning. In other words, they compared serum osmolality concentrations, plasma $\mathrm{pH}$, and lactate between admission and recovery of 13 methanol-poisoned patients and found statistically significant differences in this comparison. However, the reason for this comparison was not discussed in the article. It is well known that methanol is initially metabolized to formaldehyde and then to formic $\mathrm{acid}^{2}$. Formic acid causes a metabolic acidosis and directly inhibits mitochondrial cytochrome oxidase leading to cellular hypoxia and increase in the lactate concentrations, further exacerbating the acidosis ${ }^{3}$. Apart from this, I had some concerns regarding the management of their patients and the influences of the treatment on the studied parameters, as well. Except description about one patient who had presented with vision problem, the authors did not mention anything about their patients' symptoms and signs, hydration of their patients, and administration of sodium bicarbonate to them. They managed two patients only with ethanol because they had the lowest methanol concentration in their series. It should be pointed out that the management priorities in methanol poisoning depend upon the circumstance of presentation and not methanol concentration, per se. For instance, if the patients have any of the $\mathrm{pH}<7.25-7.30$, visual sign and symptoms, renal failure, significant electrolyte disturbances unresponsive to conventional therapy, serum methanol concentration above $50 \mathrm{mg} / \mathrm{dL}$, or deterioration in vital signs despite intensive supportive care, hemodialysis should be performed ${ }^{2}$. Furthermore, it is not clear why one of the patients was concomitantly treated with ethanol, fomepizole, and hemodialysis. Of note, fomepizole is recommended as a first-line treatment for methanol-poisoned patients who present without ophthalmologic impairment or severe acidosis ${ }^{2,4}$. In this case, fomepizole may obviate the need for hemodialysis ${ }^{2,4}$. Also, both fomepizole and ethanol alter the metabolism of each other. Therefore, co-administration of ethanol and fomepizole has not been recommended ${ }^{2}$.

The authors showed that there were no significant changes in estimated glomerular filtration rate (eGFR) between admission and recovery in their patients. Did they pay attention to the influence of hydration of the patients (if any) at hospital admission on their eGFR that might happen before taking blood samples? If so, was their sample size (only 13 patients) statistically sufficient for reaching such a conclusion?

I wonder if they considered the effects of hemodialysis and the administration of ethanol and sodium bicarbonate on $\mathrm{pH}$, serum osmolality, or correlation between osmolality and methanol level. In Table 1, I noted that there were missing data about osmolality concentrations and lactate levels at the recovery time for two and six patients, respectively. Could these missing data interfere with the accurate statistical analysis and calculation of the partial correlation coefficient between osmolality and methanol level, and lactate and methanol level?

Moreover, it is not clear what logic relationship exists between methanol poisoning and serum alanine aminotransferase for which the authors have compared this parameter between admission and recovery of the patients.

In addition, four patients had increased troponin I above $99^{\text {th }}$ percentile of healthy population. It should be mentioned that these patients had no clinical features of acute coronary syndrome and their electrocardiographs were normal. Does it really show cardiac damage in these patients?

Finally, the authors had two patients with acute kidney injury (AKI) that was developed before admission to the hospital and they could not find any explanation for that except dehydration. Could myoglobinuria have a role in the development of AKI in their patients 2 ?

\section{REFERENCES}

1. SalekT, Humpolicek P, Ponizil P. Metabolic disorders due to methanol poisoning. Biomed Pap Med Fac Univ Palacky Olomouc Czech Repub 2013 Sep 27. doi:10.5507/bp.2013.074.

2. Barceloux DG, Bond GR, Krenzelok EP, Cooper H, Vale JA; American Academy of Clinical Toxicology Ad Hoc Committee on the Treatment Guidelines for Methanol Poisoning. American Academy of Clinical Toxicology practice guidelines on the treatment of methanol poisoning. J Toxicol Clin Toxicol 2002;40:415-46. 
3. Jacobsen D, McMartin KE. Methanol and ethylene glycol poisonings. Mechanism of toxicity, clinical course, diagnosis and treatment. Med Toxicol 1986;1:309-34.

4. The College of Emergency Medicine. CME Antidote Guidelines 2008. Accessed 25 June 2012. http://www.collemergencymed.ac.uk/ShopFloor/Clinical\%20Guidelines/Clinical\%20Guidelines/default.asp (accessed May 2013).

\section{REPLY TO THE LETTER TO EDITOR}

\section{Tomas Salek ${ }^{\mathrm{a}}$, Petr Humpolicek ${ }^{\mathrm{b}, c}$, Petr Ponizil ${ }^{\mathrm{b}, \mathrm{d}}$}

aDepartment of Clinical Biochemistry, Tomas Bata Regional Hospital in Zlin a.S., Zlin Czech Republic

${ }^{b}$ Centre of Polymer Systems, Polymer Centre, Tomas Bata University in Zlín, Zlin

'Polymer Centre, Faculty of Technology, Tomas Bata University in Zlin, Zlin

dDepartment of Physics and Materials Engineering, Faculty of Technology, Tomas Bata University in Zlin, Zlin

Corresponding author: Tomas Salek, e-mail: t.salek@bnzlin.cz

Dear Professor Sanaei-Zadeh,

Thank you for your letter of comment on the article "Metabolic disorders due to methanol intoxication". It is difficult to follow the logic of the first part of your comments. Changes obvious from the outset, has no meaning. The authors mentioned high levels of serum osmolarity and metabolic acidosis on page 1 along with reasons for measuring GFR and markers of cardiac damage. Naturally, treatment resulted in improved acid base dysbalance. The authors have also provided additional details to answer your questions as follows: all patients were examined physically. This included hydration/dehydration assessment and all patients with a $\mathrm{pH}$ under 7.1 received Sodium Bicarbonate. Two only had clinical signs of dehydration but no AKI according to RIFLE criteria. Four patients were unconscious. This presented problems for us. Some of these had vomiting while the others were admitted on suspicion of alcohol intoxication. All had ophthalmological and neurological examination.Treatment with ethanol was followed by fomepizol in one patient. Treatment was closely monitorted and end of therapy was determined according to serum methanol concentration. Missing data in Table 1: There were a large number of blood samples between the first and last sampling for each patient. Some patients had physiological results a few hours after treatment. For this reason, the physician did not order all the tests at the end of the hospital stay. Relation between methanol poisoning and ALT. Nearly all drugs and toxins can increase liver test results like ALT. Troponin. Cardiac troponin I and $\mathrm{T}$ are cardio specific. They are not released from any other organ. There were 2 patients with acute kidney injury. These had no clinical signs of dehydration. Myoglobinuria as a cause of AKI. The first patient with AKI had an alanineaminotransferase (AST) level of 0:51 ukat/L and negative urine strip test for blood. Clinically significant myoglobinuria was unlikely.

You are right, a sample size of 13 is very small for statistical conclusions. Unfortunately, methanol poisoning cannot be created to satisfy medical publications. We hope that some of your questions have been answered. 